\title{
Der 100. Röntgenkongress - jetzt Abstracts einreichen
}

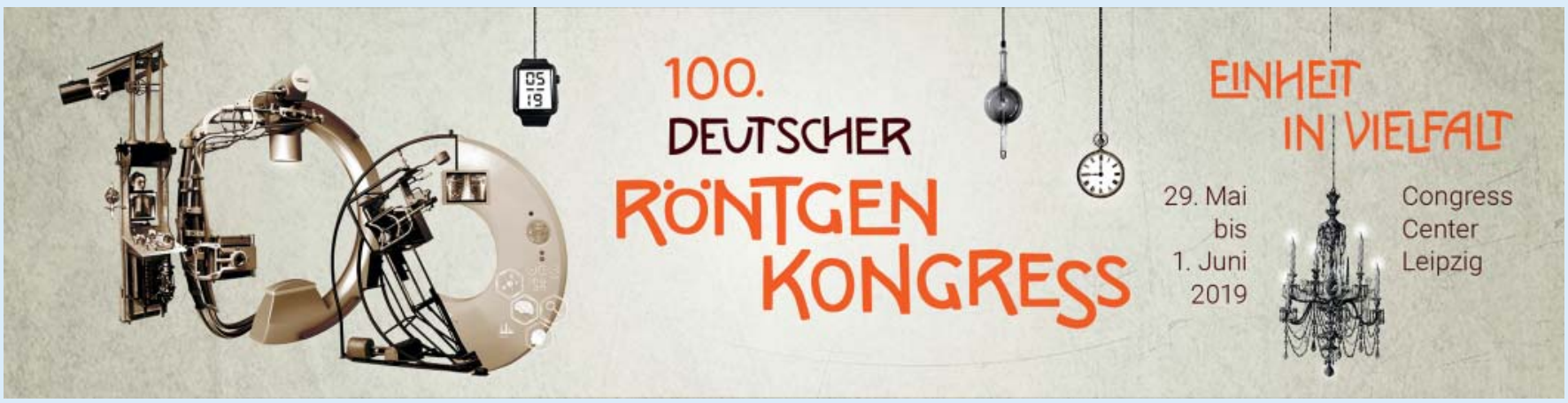

\section{Einladung zur Einreichung wissenschaftlicher Abstracts}

Wir laden Sie herzlich ein, ab sofort Ihre Abstracts für wissenschaftliche Vorträge oder Poster zu Wissenschafts- und Fortbildungsthemen einschließlich interessanter Kasuistiken zum 100. Deutschen Röntgenkongress einzureichen! Bitte reichen Sie Ihre Beiträge ausschließlich online über www.roentgenkongress.de ein. Die Frist läuft bis zum 4. November 2018, 23.59 Uhr.

Nach einer Bewertung Ihres Abstracts erhalten Sie voraussichtlich im Dezember 2018 eine Information, ob Sie mit Ihrem Beitrag auf dem RöKo 2019 präsent sein können.

Nutzen Sie diese Chance, um intensiv am wissenschaftlichen Diskurs teilzuhaben!

\section{e-Poster-Ausstellung}

Ebenfalls online über www.roentgenkongress.de können Sie einen Abstract für Ihr e-Poster einreichen. Ausgewählte Poster müssen vom Autor persönlich in täglich stattfindenden Poster-Sessions an einer
Poster-Station im RöntgenFORUM (Halle 2) auf dem 100. RöKo präsentiert werden.

Die besten Poster werden mit einem DRGPoster-Preis prämiert und anschließend in conrad, der interaktiven Lernplattform der Deutschen Röntgengesellschaft, veröffentlicht.

Werden Sie mit Ihrem Beitrag Teil der DRGWissensgemeinschaft!

\section{Wieder dabei: MTRA-Poster}

2019 können MTRA zum zweiten Mal bei einem Röntgenkongress Abstracts für eine MTRA-Poster-Ausstellung für Poster (Wissenschaft) und Poster (Fortbildung) einreichen.

Bitte beachten Sie: Geben Sie als Hauptthema unbedingt „MTRA“ an!

\section{Portal zur Hotelbuchung geöffnet!}

Die Leipziger Messe reserviert für die Teilnehmer des Röntgenkongresses umfang- reiche Zimmerkontingente in zahlreichen Hotels in und um Leipzig. Suchen Sie bereits heute das passende Hotel und buchen Sie jetzt Ihr Zimmer in Leipzig! Sie haben die Möglichkeit, Ihre Reservierung über das Online-Buchungsportal der Messe Leipzig vorzunehmen. Den Link hierzu finden Sie unter www.roentgenkongress.de. Alle hier angebotenen Zimmer werden ohne Aufschläge an Sie weitergereicht.

\section{Die Freischaltung des Portals zur Hotelbu- chung erfolgt am 1. September 2018.}

Gerne berät Sie das Team auch telefonisch bei Ihrer Hotelauswahl, beantwortet Ihre Fragen und unterstützt Sie, falls Sie besondere Wünsche haben (Mo. - Fr. 9.00 - 17.00 Uhr).

Außerhalb dieser Zeit werden Ihre Anfragen per Email entgegengenommen.

Hotel-Reservations-Team

Tel. + $49341678-8725$

Fax: + $49341678-8722$

hotelreservation-roeko@leipziger-messe.de 